\title{
Relationships of Leadership Styles of Health Care Professionals with Subordinates, Motivation, Satisfaction and Performance
}

\author{
Naresh Khatri ${ }^{1 *}$, Andrew Felker ${ }^{2}$ \\ ${ }^{1}$ Health Management and Informatics, University of Missouri School of Medicine, USA \\ ${ }^{2}$ J. Reuben Clark Law Society, Missouri Kansas, USA
}

"Corresponding author: Naresh Khatri, Health Management and Informatics, University of Missouri School of Medicine, Columbia, Missouri, USA. Tel: +1-5738842510, Email: khatrin@health.missouri.edu

Citation: Khatri N, Felker A (2018) Relationship of Leadership Styles of Health Care Professionals with Subordinates' Motivation, Satisfaction, and Performance. J Hosp Health Care Admin: JHHA-113. DOI: 10.29011/JHHA-113.000013

Received Date: 02 March, 2018; Accepted Date: 9 March, 2018; Published Date: 20 March, 2018

\begin{abstract}
A Recruitment, placement, and promotion of individuals to leadership and senior managerial positions in health care organizations are based primarily on technical competence. Unfortunately, technical competence of an individual is not a good predictor of their leadership and managerial competence. This is because the leadership/managerial role is quite complex and requires certain skills and competencies in individuals for properly performing it. In this paper, we examined the relationships of leadership styles of health care professionals of Missouri hospitals with motivation, satisfaction, and work performance of subordinates. Our findings suggest that health care leaders are less socially skill ful and they are less bold and change seeking than being knowledgeable and experienced. Consequently, they are not as effective in influencing the motivation, satisfaction, and performance of their subordinates. Health care organizations need to hire, promote, and reward leaders/managers that are highly socially skillful and that are bold and change seeking for boosting the morale and performance of health care workers.
\end{abstract}

\section{Methods}

We surveyed the employees of eight health care organizations in mid-Missouri using a leadership style instrument developed by Khatri and his colleagues [1,2]. The leadership instrument measures charismatic and visionary abilities of leaders as perceived by their followers. The survey was mailed to 400 employees of hospitals. Managers that were rated on their leadership styles included physicians and physician managers, nurse managers, finance managers, human resource managers, and other administrators. In all, 216 subordinates assessed the leadership style of their bosses $(\mathrm{N}=106)$ and how these styles influenced their motivation, satisfaction, morale, and work performance.

\section{Results and Discussion}

Our findings suggest that leadership styles of health care managers have three charismatic and visionary attributes, namely, socially sensitive, bold and change seeking, and knowledgeable and experienced. The results of multiple regression analyses showing the relationships of the leadership styles with subordinates' outcomes are presented in (Table 1) and the scales measuring these leadership styles are provided in Appendix. A glance at the results in (Table 1) suggests that social sensitivity, a charismatic attribute, is the only attribute among the above three that has a significant positive relationship with the satisfaction of followers. Further, of the three attributes, social sensitivity, shows the strongest relationship with the motivation level of subordinates. Bold and change seeking, a visionary attribute, showed significant positive relationships with motivation, morale, quantity of work, and quality of work. Its effects were particularly pronounced on motivation, morale, and quantity of work of subordinates. It did not show any significant relationship with followers' satisfaction. Knowledgeable and experienced, a visionary attribute, showed only modest relationships with motivation and quality of work. In short, socially sensitive and bold and change seeking styles have much greater influence than knowledgeable and experienced style. Social sensitivity consists of social/interpersonal skills, sensitivity to the needs and values of followers, and being a caring and friendly person. Bold and change seeking style includes behaviors such as daring to be different, challenging tradition, thinking outside the box, and driven for change. Knowledgeable and experienced style implies having broad knowledge in the field, being an expert in the field, having a lot of experience, and knowing the workings of the business well. 
Citation: Khatri N, Felker A (2018) Relationship of Leadership Styles of Health Care Professionals with Subordinates' Motivation, Satisfaction, and Performance. J Hosp Health Care Admin: JHHA-113. DOI: 10.29011/JHHA-113. 000013

\begin{tabular}{|c|c|c|c|c|c|}
\hline & Motivation & Satisfaction & Morale & Quantity of Work & Quality of Work \\
\hline Socially Sensitive & $22.16^{* * *}$ & $6.07^{* * *}$ & $3.56^{* * *}$ & -1.22 & $2.30^{*}$ \\
\hline Bold \& Change Seeking & $4.74^{* * *}$ & 1.24 & $3.22^{* * *}$ & $4.87^{* * *}$ & $1.69+$ \\
\hline Knowledgeable \& Experienced & $2.53^{* * *}$ & 0.94 & 0.95 & $1.96^{*}$ & $18.68^{* * *}$ \\
\hline Model F & $469.90^{* * *}$ & $36.68^{* * *}$ & $25.55^{* * *}$ & 0.15 \\
\hline Adjusted $\mathbf{R}^{2}$ & 0.88 & 0.36 & 0.27 & 0.21 \\
\hline
\end{tabular}

Table 1: Regression Analysis of Social Sensitivity, Bold \& Change Seeking, and Knowledgeable \& Experienced on Motivation, Satisfaction, Morale, and Quantity and Quality of Work of Subordinates (t-values).

Further, health care managers and professionals in the study sample were found to be higher on the knowledgeable and experienced dimension (mean score of 5.23 on a scale of 1 to 6 ) than on the bold and change seeking (mean score of 4.26 on a scale of 1 to 6 ) and social sensitivity (mean score of 4.81 on a scale of 1 to 6 ) dimensions. Thus, there is scope for improving the two important leadership skills - social sensitivity and bold and change seeking - of health care managers and professionals to enhance greatly the motivation, satisfaction, morale, and quantity and quality of work of health care workers.

\section{Conclusion}

We identified three important leadership styles or attributes of health care professionals, namely, social sensitivity, being bold and seeking change, and being knowledgeable and experienced. These three attributes have a highly significant effect on motivation, satisfaction, morale, and quantity and quality of work of health care professionals. Health care managers and professionals were higher on knowledgeable and experienced dimension than social sensitivity and bold and change-seeking dimensions, the dimensions that have much greater impact on followers than the knowledgeable and experienced dimension. Consequently, health care managers and professionals need to improve upon their social sensitivity and be bolder and change seeking in their approach. The important implications for recruitment, placement, and promotion of individuals for managerial and leadership positions in health care organizations are that individuals recruited and promoted to these positions should have greater social skills and be bolder and more change seeking. The usual practice of hiring and promoting individuals based merely on their technical knowledge and experience is problematic and may cause leadership deficit in health care organizations.

\section{References}

1. Khatri N, Templer KJ, Budhwar P (2012) Great (transformational) leadership $=$ charisma + vision. South Asian Journal of Global Business Research 1: $38-62$.

2. Khatri N, Ng HA, Lee TH (2001) The distinction between charisma and vision: An empirical study. Asia Pacific Journal of Management 18: 373-393. 